requiring detailed follow up to four patients per week, which might be a more realistic target for most hospitals. All deaths from trauma would also need to be included in the audit.

The next phase of the audit is to include all the admissions of patients with serious injuries in Sheffield and to include deaths occurring out of hospital.

As many hospitals as possible should take part in the full audit and submit their data to the major trauma outcome study (UK) as only by gathering data on large numbers of patients can the analysis be amended to provide valid outcome norms for the United Kingdom.

We thank the senior house officers and other staff in the accident and emergency department of the Northern General Hospital for their work in this project and the consultants and medical records staff of the hospital and other Sheffield hospitals for their help. SFC is supported by a grant from Trent Regional Health Authority.

I Gennarelli TA, Champion HR, Sacco WJ, Copes WS, Alves WM. Mortality of patients with head injury and extracranial injury treated in trauma centers. Trauma 1989;29:1193-1202.

2 Boyd CR, Tolson MA, Copes WS. Evaluating trauma care: the TRISS method. f Trauma 1987;27:370-8.

3 American Association for Automotive Medicine. The abbreviated injury scale, 1985 revision. Arlington Heights, Illinois: AAAM, 1985.

4 Baker SP, O'Neil B, Haden W, Long WB. The injury severity score: a method for describing the patient with multiple injuries and evaluating emergency care 7 Trauma 1974;14:187-96.

5 Royal College of Surgeons of England. The management of patients with major injuries. London: RCS (Eng), 1988 .

6 Gilchrist WJ, Newman RJ, Hamblen DL, Williams BO. Prospective randomised study of an orthopaedic geriatric inpatient service. Br Med f 1988;297: ised s. $116-8$.

Foubister G, Hughes SPF. Fractures of the femoral neck: retrospective and prospective study. F $R$ Coll Surg Edinb 1989;34:249-52.

(Accepted 6 March 1990)

\title{
Extending the use of clinical audit data: a resource planning model
}

\author{
Brian W Ellis, Richard C Rivett, Hugh A F Dudley
}

\section{Abstract \\ Objective-Tồ create a means by which we can} examine and understand the interrelations among the fundamental elements of hospital inpatient care (patients, beds, theatre time, and staff).

Design-Predictive study of resource utilisation based on a computerised clinical information system of five years' audit data from a surgical management system.

Setting - One surgical firm (of one consultant, one registrar, and one preregistration houseman) in a district general hospital.

Patients - 5267 Patients whose admission records were part of the five years' audit of surgical management.

Main outcome measures-Mean length of stay; number of occupied beds; turnover interval; throughput (patients/bed); percentage elective theatre occupancy; waiting time for elective admissions; and theatre, hotel, and total costs.

Results-Predicted outcome was analysed in the model, taking the actual outcomes in 1988-9 as baseline values, for four clinical scenarios: an increase in accident and emergency admissions, a reduction in beds, a reduced length of stay, and creation of a new firm. Baseline values showed a mean stay of just over five days in $\mathbf{1 5}$ beds and with a theatre occupancy of $94 \%$; the total cost was $£ 812000$ (hotel costs $£ 597000$ ). Increasing the accident and emergency admissions to 460 /year (19\%), based on projected trends from 1984 to 1988 , resulted in increased hotel costs $(\$ 55000)$ and reducing bed numbers (by halving admissions) in decreased use of theatres to $71 \%$, decreased throughput, and increased waiting time, from 20 to 92 weeks, at a saving of $\$ 99000$ (12\%). Reducing stay marginally reduced bed occupancy $(8 \%)$ and hotel costs $(14 \%)$, and creating a new surgical team considerably reduced bed occupancy $(14 \%)$ and waiting time for elective operations (by $20 \%$ ). The minimum number of beds for referrals, accident and emergency admissions, and planned admissions was 9.0 ; that for urgent elective admissions was 3.3 and for nonurgent admissions was $2 \cdot 4$.

Conclusion-A well designed clinical information system with the routine collection of data can provide the necessary output data to enable resource modelling.

Implication-Use of such a model will allow clinicians to participate in resource planning on the basis of what is actually happening within the hospital.

\section{Introduction}

Resource management, introduced by the Department of Health and Social Services during 1987-8, has as its fundamental principle the notion that better information leads to improved utilisation of available resources. The exact nature of the information needed has still to be defined by pilot studies, but it seems inevitable that clinical activity will be the main variable cost and thus attention should be directed at measuring such activity. For numerical information on clinical activity to mirror the real world, however, it must be both comprehensive and faithful to what has really happened. Much evidence suggests that the current clinical input does not fulfil these requirements. ${ }^{1-3}$ Existing methods of data collection are hampered by the failure of consultants and their junior staff to make the relevant data easily available in their patients' medical records. A lack of appreciation of the importance of the exercise, coupled with the scarcity of relevant feedback of information derived from the data, is probably responsible for the minimal motivation with which many clinicians approach the task of data handling. The problem is compounded in the medical records departments of many hospitals, where record clerks, who have no medical training, display low morale because they have little incentive. They must find case notes and, having deciphered longhand or typescript, assign an International Classification of Diseases (ninth revision) diagnostic code ${ }^{4}$ from one set of manuals and an Office of Population Censuses and Surveys (OPCS Revision 4) procedure code ${ }^{5}$ from another. In some hospitals the staffing and performance of these departments are both so low that many discharges are not coded.

One alternative is for the clinical input for resource management to originate from an automated clinical management system, used to run the clinical unit for audit and other purposes. Input by the clinical team is used by them for judging the effectiveness and efficiency of clinical performance, ${ }^{6}$ but there is considerable overlap of the basic data required for this purpose and for the best management of resources.

We present an application of a clinical management system designed primarily for audit and the running of 
the admission and discharge system of a surgical unit to the more general .task of modelling resource management.

\section{Methods}

MANAGEMENT SYSTEM

In 1985 we began to collect data on to a MICROMED surgical management system (Medical Systems) designed by clinicians in association with computer professionals, which we have previously described. Although all three surgical firms now enter their clinical data on to the system, the information obtained for this study represents the clinical activity of a single firm or team of one consultant, one registrar, and a preregistration houseman. When the system was set up we retrospectively entered data on patients back to September 1984; we now have five years of information on 5267 admissions from that firm. The first box shows the data available from the system relevant to this study.

For the resource planning model (see below) data collection and analysis were by source or mode of

\section{Data extracted from MICROMED system for resource planning model}

No of patients discharged by source

Mean stay length by source

Elective operations by source and by grade

Emergency operations by source and by grade

No on waiting list by priority (urgent, soon, and routine)

No of additions to waiting list by priority per year Waiting time by prioritiy at end of past year

TABLE I-Assumptions made in costing use of theatres

\begin{tabular}{ccc}
\hline Grade of operation $^{\star}$ & Cost/h $(\mathfrak{£})$ & Duration $(\min )$ \\
\hline Minor & 175 & 30 \\
Inter & 225 & 45 \\
Major & 300 & 75 \\
Major plus & 400 & 150 \\
\hline
\end{tabular}

$\star^{\star}$ Categories based on operation grading by British United Provident Association.

TABLE II - Resource utilisation based on input data derived from 84 items of audit data, according to four clinical scenarios

\begin{tabular}{|c|c|c|c|c|c|}
\hline \multirow[b]{2}{*}{ Key input variable $\star^{\star}$} & \multirow[b]{2}{*}{$1988-9$} & \multicolumn{4}{|c|}{ Scenariost } \\
\hline & & A & B & $\mathrm{C}$ & $\mathrm{D}$ \\
\hline & Input & & & & \\
\hline \multicolumn{6}{|l|}{ No of discharges by source of admission: } \\
\hline Accident and emergency & 388 & 460 & & & 290 \\
\hline Referral & 42 & & & & 31 \\
\hline Elective (urgent) & 217 & & & & \\
\hline Elective (soon) & 198 & & 100 & & 208 \\
\hline Elective (routine) & 158 & & 80 & & 166 \\
\hline Planned & 139 & & & & \\
\hline \multicolumn{6}{|l|}{ Length of stay by source of admission (days): } \\
\hline Accident and emergency & $7 \cdot 0$ & & & $6 \cdot 4$ & \\
\hline Referral & $11 \cdot 2$ & & & $10 \cdot 3$ & \\
\hline Elective (urgent) & 5.6 & & & $5 \cdot 0$ & \\
\hline Elective (soon) & $3 \cdot 2$ & & & $3 \cdot 0$ & \\
\hline Elective (routine) & 1.6 & & & 1.5 & \\
\hline Planned & $1 \cdot 0$ & & & $1 \cdot 0$ & \\
\hline \multicolumn{6}{|c|}{ Output } \\
\hline Mean length of stay (days) & $4 \cdot 8$ & 4.9 & $5 \cdot 2$ & $4 \cdot 4$ & $4 \cdot 4$ \\
\hline No of occupied beds & 14.9 & $16 \cdot 2$ & $13 \cdot 7$ & $13 \cdot 7$ & $12 \cdot 8$ \\
\hline Turnover interval (days) & $0 \cdot 7$ & $0 \cdot 2$ & $1 \cdot 4$ & $1 \cdot 1$ & 1.5 \\
\hline Throughput (patients/bed) & 67 & 71 & 56 & 67 & 62 \\
\hline$\%$ Theatre occupancy (Elective) & 94 & 95 & 71 & 94 & 93 \\
\hline Waiting time (elective (soon) admission (weeks)) & 14 & 14 & 79 & 14 & 11 \\
\hline Waiting time (elective (routine) admission (weeks)) & 20 & 20 & 92 & 20 & 16 \\
\hline Theatre cost $(£ 000)$ & 215 & 223 & 171 & 215 & 206 \\
\hline Hotel cost $(£ 000)$ & 597 & 652 & 541 & 514 & 512 \\
\hline Total cost $(\mathfrak{£} 000)$ & 812 & 875 & 713 & 756 & 718 \\
\hline
\end{tabular}

*Only when an input data item varies from the 1988-9 data is it shown in the input panel at the top.

$+\mathrm{A}=$ continuing increase in accident and emergency admissions; $\mathrm{B}=$ reduction in bed numbers to save money, $\mathrm{C}=$ reduced length of stay; $\mathrm{D}=$ creation of a surgical team.

\section{Modes of admission}

From accident and emergency department

Internal or other hospital referral

Elective - urgent

$$
\text { - soon }
$$$$
\text { - routine }
$$

Planned (for example, check cystoscopy)

admission (second box). This approach was used because it seems reasonable to argue a priori that the only control that clinicians have over the patterns of their activity is by regulating the flow of patients awaiting admission. Accident and emergency admissions are analysed separately from referrals and the three priorities of elective work. Planned admissions are those in which patients' entry to hospital is scheduled after a fixed interval (for example, check cystoscopy and for repeated chemotherapy); they do not, by definition, contribute to waiting time.

\section{PATIENTS AND RESOURCES}

Patients from a given source of admission have a distinct pattern of resource utilisation which may be integrated from: number of discharges, mean length of stay, use of emergency or elective theatre, and the severity of the operation performed. Data on bed cost were supplied by the district finance department, the figure of $£ 110$ per night including all overheads except those relating to theatres. Theatre overheads and the cost of the operation were based on assumptions in table I and were derived from an analysis of a random selection of theatre sessions, including an estimate from the theatre register of the time taken for the operation and of the staff and equipment involved. Continuously derived real data will be substituted once a computer based theatre management system currently being implemented is in place.

\section{ANALYSIS}

Eighty four data items were combined with standard formulas of the type currently in use in every health district $^{8}$ to derive the output shown in table II. The data and the formulas were loaded manually on to a standard, commercially available spreadsheet (Microsoft Multiplan V3), which enables rapid recalculation for modified input variables. We were then able to examine several scenarios often discussed by clinicians and managers and about which arbitrary decisions are frequently taken, such as the problem of the emergency load, limited elective admissions, reduced length of stay, or the introduction of new facilities such as an extra surgical team to cope with demand.

\section{Results}

ANALYSIS OF PRIMARY DATA

The "mix" of sources of admission and modes of admission showed little variation over the five years, though the number of discharges rose steadily. Figure 1 shows the totals and proportion of discharges by source of admission. Though urgent and elective (soon) admissions seemed to have increased, we think that this has resulted from an alteration of the thresholds among classes of priority, which inevitably occurs as a waiting list grows. Thus when waiting time for admission is excessive only patients with the most innocuous conditions will be classified as routine admissions.

Table II summarises, in its first column, the outputs generated for the actual patient input in 1988-9. The mean stay was just under five days in 15 beds and the elective theatre occupancy was $94 \%$. The total cost of 


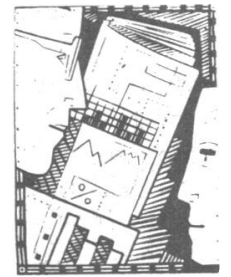

the team's activity was $£ 812000$, of which $£ 597000$ was hotel costs.

\section{CHANGING THE CLINICAL SCENARIO}

There are an almost unlimited number of ways by which it would be possible to alter the input variables to provide different combinations of outputs. Some underlying pragmatic hypothesis may narrow the possibilities. Examination of our outpatient data showed a steady increase in the waiting time for elective surgery (fig 2). Up to 1988-9 there was also a growth in emergency workload. This suggests that a continuous increase in the emergency load was "squeezing out" elective surgery. We therefore took this idea as the starting point to examine four clinical scenarios.

Scenario A: What if the accident and emergency load continues to increase? - We reset the accident and emergency admissions to 460 a year, basing this $19 \%$ increase on a visual extrapolation of the trend of admissions from 1984-5 to 1987-8. Mean length of stay increased marginally, and the number of occupied beds rose from 14.9 to $16 \cdot 2$. Elective theatre occupancy also rose slightly as a result of the additional nonemergency surgery that would be performed for the extra accident and emergency admissions. Total elective and emergency theatre costs increased by $£ 8000$.
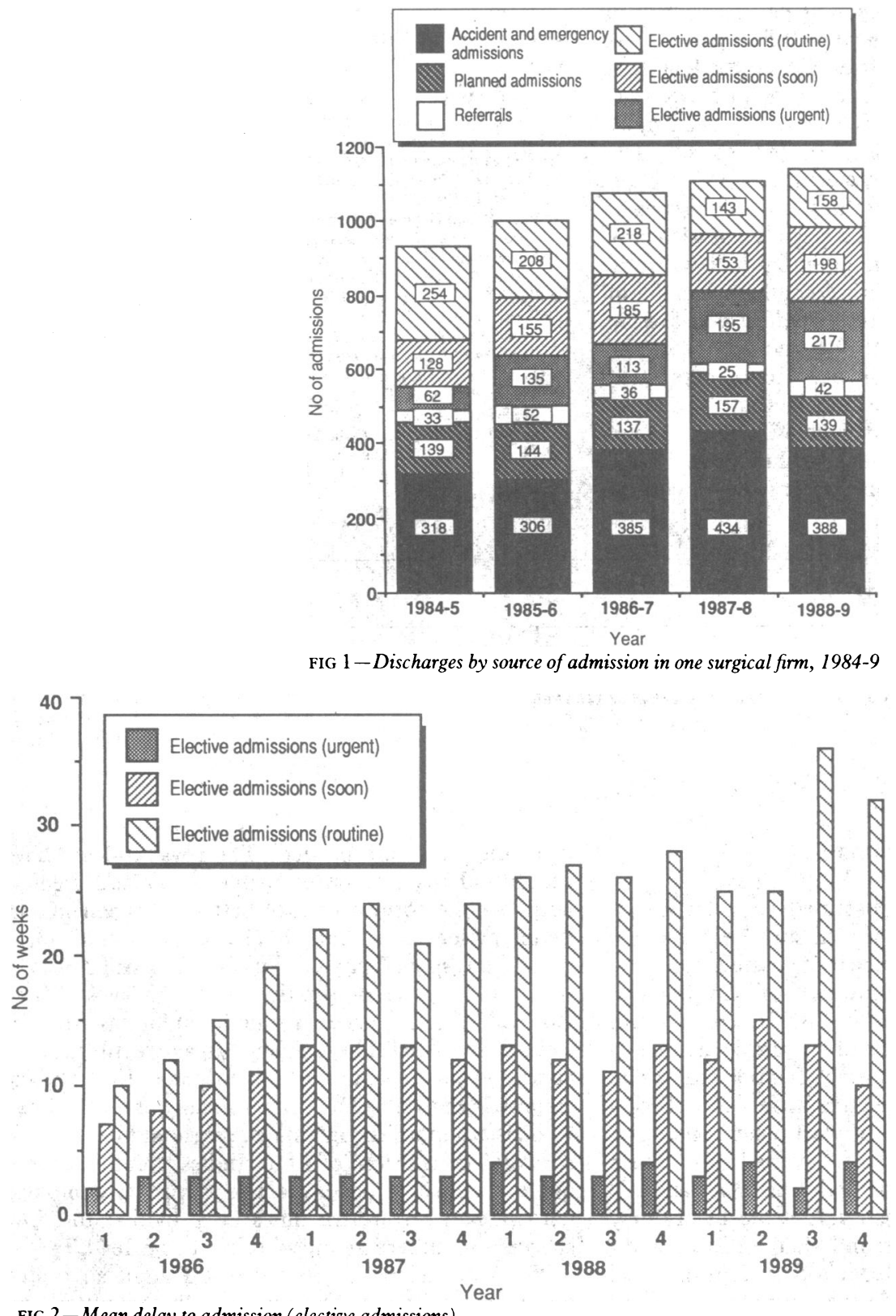

\section{Output from resource planning model}

Total and percentage bed days Hotel, theatre, and total costs Elective theatre costs and hours

Emergency theatre costs and hours admission

Mean stay length

Occupied beds

Turnover interval

Throughput

$\%$ Theatre occupancy

Emergency hours per week

The most notable effect, however, was the increase of $£ 55000$ in hotel costs.

Scenario B: What if bed numbers had to be reduced to save money? - A familiar scenario is external financial pressure being used to dictate rationalisation (that is, closure) of beds. As a consequence it is then assumed that if, as scenario A suggests, it is not possible to check the rising accident and emergency load then nonurgent elective admissions have to be reduced until bed constraints are met. To illustrate the effects of this we took the somewhat extreme case of reducing these admissions by half. Such a cutback is necessary to achieve even a modest reduction of 2 beds. Utilisation of the operating theatres was reduced to $71 \%$, throughput dropped to 56 per bed (a reduction of 16\%), and waiting time for routine admissions at the end of just one year rose from 20 to 92 weeks. The financial saving associated with this profound effect on waiting time was $£ 99000(12 \%)$.

Scenario C: What if length of stay is reduced? - It is a management goal to find better ways of utilising resources, hence clinicians are under continual pressure to seek what are regarded, in isolation, as cost effective measures. One such measure is ever earlier discharge. We used an overall reduction of $8.5 \%$ in the model while keeping the case load fixed. The outcome was a marginal reduction in occupied beds $(8 \%)$ to the same figure as in scenario B. There was no change in theatre use, in throughput, or in waiting time because of the constant patient load. There was an expected but notable drop in hotel costs, of $£ 83000$ (14\%).

Scenario D: Can we create another surgical team? The addition of another team (in our case from three to four) should reduce the accident and emergency load and internal referrals, we assumed by a quarter in both cases, but, as past experience has shown, there was likely to be little or no effect on the addition of patients to the waiting list of the existing teams. Elective work in the existing team would increase (by say 5\%) as numbers of accident and emergency admissions fell. The number of occupied beds fell considerably (14\%); theatre occupancy also declined slightly, to $93 \%$. The waiting time for routine elective operations, however, was reduced to 16 weeks $(20 \%)$ by the end of the first year. Costs for the existing team were reduced by $£ 94000$ (13\%).

In addition to these scenarios, we also used the model to calculate that nine beds is the minimum required to treat patients whose admission is beyond the control of the clinical team (that is, patients admitted as referrals, accident and emergency admissions, and planned admissions). To treat patients admitted as urgent elective surgery a further 3.3 beds are needed; thereafter only 2.4 more beds are necessary for non-urgent elective surgery. Waiting list "initiatives" have also stimulated us to investigate costing an additional three hour theatre session; in this case theatre expenditure rose by $£ 32000$ and hotel costs by $£ 50000$. The waiting time for non-urgent admissions, however, was reduced to five weeks at the end of one year. 


\section{Discussion}

Our use of this form of modelling is designed to show two points. Firstly, that the availability of clinical information at team level permits resource modelling which, however crude, is based on accurate inputs. Until now doctors have had little confidence in the validity of results produced from hospital derived data. Secondly, such modelling throws considerable light on how certain and often recommended changes do or do not have financial or resource implications of the kind predicted from the usual naive assumptions we all tend to make. The example of changing the emergency load (scenario A) indicates what has been termed "sensitive dependence on initial conditions." That of limiting elective admissions (scenario B) indicates how financial savings can be met only at the expense of service to patients. In management terms it also shows that nonurgent admissions (soon or routine) are "efficient" (31\% of all patients treated but occupying only $16 \%$ of the beds). Reducing the number of these admissions has only slight effects on work patterns at the human cost of greatly increasing waiting time.

Scenarios C and D put numerical and financial flesh on to options that are all too often pursued because it is thought that they might help. Of course we recognise that scenario $\mathrm{C}$ (reducing length of stay) in its present form cannot measure the community costs of early discharge or the potentially disturbing effects on nursing of a decreased number of patients who can fend for themselves while they are still inpatients. As over the past five years we have reduced the length of stay of inpatients by $20 \%$ we have been impressed how this pressure has increased. We urgently need more information on the total implications of an early discharge policy in a busy surgical unit.

The process of audit should deal with the issues of efficiency and effectiveness. This paper deals with only the former and examines the potential link with the economic considerations embraced in the principles of resource management. The study of effectiveness is no less important. The patient, the manager, and the district audit committees will need to be persuaded that clinicians are taking a critical look at the quality and outcome of the care they deliver. When we begin to get to grips with these questions, and they are no less complex, there will be an even greater need for clinical information systems to be able to integrate with resource management.

Finally, it can be argued that our system is merely a resource management initiative at team level and thus does not have any broader application. This may be so, but it has the great advantage that, once set up in relation to the basic clinical management system, it does not require any special data collection over and above that which occurs in routine clinical care. It also allows clinicians to take an active and even initiating role in planning-always provided a manager can be persuaded to believe the figures produced by the team.

In less than a year hospitals in the United Kingdom will be "selling" their services to district health authorities. Hospital managers will need an effective resource management tool in which both they and their clinicians can have confidence. The medical profession needs to appreciate very soon the need for accurate clinical data so that meaningful information may be derived from it.

Our modelling can be performed by anyone who has collected at least a year's accurate inpatient information. If he or she is then faced with debate with management colleagues' or with the task as head of a clinical directorate of preparing objectives and goals or merely wishes to pursue efficiency ${ }^{10}$ the technique allows the preparation of what amounts to a clinical business plan. It is possible, with this to hand, to argue for change in resource allocation based on what is actually taking place.

1 Whates PD, Birzgalis AR, Irving M. Accuracy of hospital activity analysis operation codes. Br Med F 1982;284:1857-8.

2 Rees JL. Accuracy of hospital activity analysis data in estimating the incidence of proximal femoral fracture. $\mathrm{Br}$ Med $\mathcal{F}$ 1982;284:1856-7.

3 Crawshaw C, Moss JG. Accuracy of hospital activity analysis operation codes. BrMed F 1982;285:210.

4 World Health Organisation. Manual of the international statistical classification diseases, injuries and causes of death. Revision 9. Geneva: WHO, 1977

5 Office of Populations Censuses and Surveys. Classification of surgical operations. 4th ed. London: OPCS, 1986

6 Ellis BW. How to set up audit. Br Med f 1989;298:1635-7.

7 Ellis BW, Michie HR, Esufali ST, Pyper RJD, Dudley HAF. Development of a mcrocomputer based system for surgical audit and patient administration: a review. $\mathcal{F} R$ Soc Med 1986;80:157-61.

8 Day C. From fugures to facts. London: King's Fund, 1985.

9 Skinner PW, Riley D, Thomas EM. The use and abuse of performance indicators. Br Med T 1988;297:1256-9.

10 Wyllie JH, Kidson IG, Wyllie DH. Pursuing efficiency in surgical practice. BrMed f 1988:297:1368-71.

(Accepted 20 April 1990)

\section{Royal Sussex County Hospital, Brighton BN2 5BA \\ Robert Gumpert, FRCS, consultant general and vascular surgeon Cynthia Lyons, MPHIL, research coordinator (medical audit) CASPE Research}

Correspondence to: Mr Gumpert.

BrMed f 1990;301:162-5

\title{
Audit in Person
}

\section{Setting up a district audit programme}

\author{
Robert Gumpert, Cynthia Lyons
}

\section{Why a district audit programme?}

The white paper declares that medical audit is "intended to provide the necessary reassurance to doctors, patients, and managers that the best possible quality of service is being achieved within the limits imposed by the resources available"; that "it should become part of routine professional practice and, in particular, that its use must form part of the training of junior staff'; that it "must not discourage doctors from undertaking difficult, but essential, clinical work where there is a known element of risk"; and that "every doctor should participate in regular systematic medical audit." It acknowledges that the quality of medical work may be reviewed only by peers and that effective audit requires specialised knowledge of current medical practice. But new methods of measuring the outcome of medical care are needed. The royal colleges have recognised that "resource management and medical audit are the cornerstones of better management and better patient care" and concluded that "audit must remain a responsibility of clinicians and will continue to be a prime responsibility of the colleges." The Royal College of Surgeons stated that "it has been for some time official college policy to make regular audit a condition of recognition of hospitals for surgical training"; that "absolute confidentiality of results must be insisted upon, though managers should have access to overall conclusions of audit studies"; and that "adequate sessional time, secretarial support, computer hardware and software must be provided to allow surgeons to undertake the additional workload."

The working paper 6 on medical audit advocates district audit being led by a local audit committee (the 